\title{
IMPACT OF DEPRESSION ON THE INTEGRATIVE COMPLEXITY OF TEENAGERS IN PAKISTAN
}

\author{
ZAYNA K. MIAN, RAAFIA R. KHAN, ANDLEEB ZAHRA, \& \\ Dr. FERIHA PERACHA
}

https://doi.org/10.37602/IJSSMR.2022.5106

\begin{abstract}
Low cognitive complexity, characterized by categorical thinking that does not recognize the validity of different viewpoints, is an important psychological predictor of radical views and violence in youth. Research shows that some of the stressors that increase the vulnerability of individuals to low complexity and constrained thinking include family issues, traumatic events, and threats to identity. Given the recent increase in mental health issues in adolescence, this paper examines whether depression has an impact on the Integrative Complexity (IC) of teenagers. Results of the study on a group of students from an SOS Village school in Pakistan show that depression levels have a significant negative correlation to value complexity $(r=-.474)$ in youth. These findings highlight the need to explore interventions in teenagers to reduce the impact of depression on their cognitive ability and limit susceptibility to extremist views and violence.
\end{abstract}

Keywords: Integrative Complexity, Depression, Extremism, Teenagers, IC Interventions

\subsection{INTRODUCTION}

Integrative Complexity (IC) is psychometric that gives a window into a person's cognitive perception of the world. It measures the approach taken by individuals or groups in processing information and solving problems based on their ability to recognize and accept that there can be more than one legitimate point of view on an issue (differentiation), and reach a reasoned judgement by forming logical links between varying perspectives (integration) (Suedfeld, 1985; Bekes \& Suedfeld, 2019). Low IC is associated with black and white thinking, whereas high IC is indicative of flexible thinking, that can encompass pluralism in perspectives.

The body of literature on IC includes applications in political psychology (e.g., Suedfeld \& Tetlock, 1977; Porter \& Suedfeld, 1981; Suedfeld, Wallace \& Thachuck, 1993); personality and performance (Gruenfeld \& Hollingshead, 1993); and extremism and violence (e.g., IC Thinking, 2018). Research by IC Thinking reveals that high complexity enables individuals to make reasoned judgements and perceptions that are balanced, which result in fewer extreme viewpoints and less susceptibility to violence. Low cognitive complexity, characterized by categorical thinking that does not recognize the validity of different viewpoints, is an important psychological predictor of radical views and violence. 


\title{
International Journal of Social Sciences and Management Review
}

\author{
Volume: 05, Issue: 01 “January - February 2022"
}

ISSN 2582-0176

Some of the stressors that increase the vulnerability of individuals to low complexity and constrained thinking include family issues, traumatic events, and threats to identity (Nemr and Savage 2019). The identification of such social and psychological stressors in youth is critical for identifying groups that may be susceptible to the influence of extremist ideologies and for designing targeted interventions to reduce their vulnerabilities. Throughout the teenage years, physical changes are accompanied by psychological changes, as well as major developments in skills such as logical, rational, and moral thinking (WHO, 2020). Thus, the development of IC is most significant throughout the teenage years. Recent studies suggest that this period of development, involving rewiring of the brain and hormonal fluctuations, also coincides with a trend showing a rise in mental health issues including depression in adolescents (Public Health England, 2019; NIMH, 2021). Therefore, this paper analyses the impact of depression on IC by investigating the hypothesis that depression has a negative correlation with the value complexity of teenagers.

\subsection{SIGNIFICANCE AND APPLICATIONS IC}

The rise of extremism and violence over the last several decades has led to the development of a robust body of literature by researchers at IC Thinking (Cambridge) on the role of cognitive complexity in predicting susceptibility to extremist thinking and designing interventions to prevent violence. The role of low IC, as one of the contributing factors to violence motivated by religious beliefs, was highlighted by Savage and Liht $(2008 ; 2009)$, which subsequently led to the development of an intervention based on promoting high IC thinking to preempt the participants of the Being Muslim Being British (BMBB) course from pursuing religious extremism (Savage 2012; Liht and Savage, 2013). The BMBB intervention consisted of 16-hour contact with a group of 81 young Muslims exposed in seven pilot studies across the UK to a range of value priorities, who were shown films and engaged in group activities to encourage their own exploration of personal value spread and building cognitive complexity. The intervention aimed to bring a transformation in the tendency of young participants inclined to value monism (where one value needs to be realized to the exclusion of all others) associated with low IC, towards value complexity associated with complex thinking and high IC, in order to improve their ability to resolve conflicts through compromise and cooperation.

The above intervention using IC to help reduce violence and extremism was adapted and introduced in Pakistan through Social Welfare, Academics and Training for Pakistan (SWAaT, local NGO) and the Pakistan Army, to rehabilitate adolescent and pre-adolescent male militants captured in 2009 as a part of a counter-terrorism operation (Peracha et al., 2016). SWAaT also worked towards preventing violent extremism in regions most vulnerable for militant recruitment through interventions in selected mainstream public schools aimed at developing skills at the core of IC such as critical thinking, logical reasoning, the multiplicity of perspectives, and traits like empathy.

Recently, Savage and Fearon (2021) report an increase in cognitive complexity related to an intervention to reduce ethnic tension and extremist views in Bosnian youth. Examples of earlier IC interventions include the prevention of violent extremism in Kenya and interventions in secondary schools in Northern Ireland to counter conflict. Boyd MacMillan et al. (2016) reported a successful intervention in Protestant-Catholic sectarianism conflict in 


\title{
International Journal of Social Sciences and Management Review
}

\author{
Volume: 05, Issue: 01 “January - February 2022"
}

ISSN 2582-0176

Scotland, where "participatory theatre and experiential methods" were used to increase cognitive complexity. Their findings showed the potential for the positive impact of IC interventions in promoting psychosocial well-being in the community and reducing sectarianism. Being Muslim Being Scottish (Boyd MacMillan, 2016), is another example of a study designed to increase cognitive complexity and promote value pluralism, by enabling participants to identify and accept a wider range of outcomes in situations of conflict rather than adhering to value monism associated with black and white thinking.

Although it is well established that IC promotes skills such as critical thinking and social intelligence, which can enhance personal development in tandem with promoting tolerance, peace and harmony in communities; there are still gaps in our understanding regarding the impact of internal and external stressors on the development of IC in youth. Nemr and Savage (2019) identify some stressors that increase the vulnerability of individuals to low complexity and constrained thinking such as family issues, traumatic events, and threats to identity. With regards to the impact of emotional well-being on IC, a study by Kargar et al. (2013) showed that teaching critical and creative skills to 40 students in Tehran, for a duration of 10 sessions (20 hours), resulted in a substantial increase in psychological wellbeing and a sharp decrease in external "locus of control" of the adolescents. The creative and critical skills imparted to the students helped them analyse, evaluate and process information; build innovation, autonomy and control abilities; which in turn helped improve their psychological well-being. However, the study discounted certain aspects of IC as the psychological well-being of students in relation to critical thinking was not assessed using their baseline ability, but rather assessed after 20 hours of extensive training.

A study by Fearon and Boyd Mac-Millan (2016) focuses on the impact of stress, a key determinant of emotional well-being, in the context of conflict. They take into account the 'Disruptive Stress hypothesis', which highlights how IC levels decrease in times of high stress; however, a predominant portion of their research confirms that this may not always be the case. On the contrary, the stress in times of complexity can be attributed to whether the situation is perceived as a challenge-response or a threat response. Based on the Biopsychosocial (BPS model), a challenge-response can actually increase IC levels due to being "associated with improved cognitive performance, willingness to consider other viewpoints and greater positive effect". From a physiological perspective, a challengeresponse stimulates the Sympathetic Adrenal Medullary (SAM axis), which simultaneously increases heart rate, while enabling maximum blood flow to the muscles and the brain to face the challenge (Liht and Savage, 2013). On the other hand, a threat response stimulates the Hypothalamic-Pituitary-Adrenal (HPA) and SAM axes that elevate heart rate and cortisol levels in the blood, which correspond with increased stress levels that can impact emotional well-being (Blasovich and Mendes, 2010).

Fearon and Boyd Mac-Millan (2016) essentially conclude that "interventions that seek to leverage gains in integrative complexity must also learn how to leverage stress", thus providing insight on how to regulate and control stress responses so that they enhance instead of disrupting IC, which is necessary for peaceful solutions in conflict. Although their research establishes a firm link with stress having an impact on IC, it does not focus on other factors contributing to psychological well-being. Since the correlation of IC and stress has so far been viewed in the context of conflict situations only, it will be useful to analyze the 


\title{
International Journal of Social Sciences and Management Review
}

\author{
Volume: 05, Issue: 01 “January - February 2022"
}

ISSN 2582-0176

correlation of stress and IC in a wider context, while considering other indicators of psychological well-being, such as depression to help develop more targeted interventions for youth.

This study aims to fill this gap by examining the role of depression on IC in teenagers, with a focus on Pakistan, as mental health issues are on the rise in youth all over the world.

According to the World Health Organization (WHO, 2020), 16\% of the global burden of disease is due to mental health conditions in adolescents, while depression is one of the leading causes of illness in this age group and suicide is the fourth leading cause of death in the 15-19 years age group. Data on mental health in Pakistan is limited. According to the WHO, mental health disorders in Pakistan account for more than $4 \%$ of the total disease burden where approximately 24 million people are in need of psychiatric assistance. A study on school children in northern Pakistan showed depression in $17.2 \%$ of participants linked to poor economic status and negative events in life (Khalid et al., 2019). With the rise of the Covid-19 pandemic and associated economic upheaval, there is an urgent need for studies on the emotional well-being of adolescents in Pakistan.

Although data on mental health may be limited in Pakistan, studies in other parts of the world confirm a rise in disorders such as depression in adolescents. For example, a survey of mental health of young people in England showed that " $12.5 \%$ of 5 to 19 -year-olds had at least one mental disorder when assessed (2017), and 5\% met the criteria for 2 or more mental disorders. There also appears to be a slight increase over time in the prevalence of the mental disorder in 5 to 15 -year-olds, rising from 9.7\% (1999) to $10.1 \%$ (2004) to $11.2 \%$ (2017)" (Public Health England, 2019). Another study on European teenagers showed a decline in mental well-being in school going children between the years 2014 to 2018, with adolescent girls being more impacted (DW, 2020). A study on children in Sub Saharan Africa found one in seven suffering from a mental health illness (Cortina et al., 2012). Data on mental health challenges in children from the Centers for Disease Control and Prevention (CDC, 2021) in the US shows that the most commonly diagnosed mental disorders in children include ADHD, behaviour problems, anxiety, and depression. Moreover, the National Institute of Mental Health (NIMH, 2021) reports that as per the '2019 National Survey on Drug Use and Health, $15.7 \%$ of the US population between the age group of 12 to 17 years had at least one major depressive episode, with higher prevalence incidence in females. Since the emotional well-being of teenagers is volatile during this critical phase of development, it remains to be seen if disorders like depression can have an impact on their IC, which in turn correlates with critical thinking skills, ability to cope and process stress, and susceptibility to violence.

\subsection{METHODOLOGY}

The study group was selected from a middle school for boys, with a student body representative of a low socio-economic background, operated by SOS Village in Lahore, Pakistan. Permission for conducting the study was taken in collaboration with SWAaT, which has prior experience in conducting IC interventions in Sabaoon to deradicalize young militants and introduce IC courses in select government schools. Surveys were conducted over a two-day period in July 2021 in the presence of a school teacher, author and 


\section{International Journal of Social Sciences and Management Review}

Volume: 05, Issue: 01 “January - February 2022”

ISSN 2582-0176

psychologists from SWAaT to help clarify any questions related to the administration of the questionnaires.

\subsection{Sample Selection}

Sample size consisted of 37 boys between grades 7 to 9 , from SOS Village Hermann Gmeiner school in Lahore. The mean age of the boys was 13.32 ( $\mathrm{SD}=3.36)$.

\subsection{Assessment Measures}

Two measures for assessment were finalized based on SWAaT psychologists' prior experience with IC in Pakistan (Peracha et al., 2016) and other IC studies.

\section{Siddiqui Shah Depression Scale}

To gain insight into the well-being of teenagers, with a particular focus on depression, the Siddiqui Shah Depression scale (SSDS) was used. SSDS contains 36 items with a 3-point scale with questions regarding thoughts, feelings and emotions, which are context-specific to people residing in Pakistan (Siddiqui and Shah, 1997). Participants were allowed to choose from 4 options: never, sometimes, often, and all the time. The maximum possible score was 108 (a 0,1,2,3 scale was used), with mild depression between 0-26, the moderate depression between 27-50, and severe depression being 50 and above.

\section{Social Dilemma Questionnaire}

The Social Dilemma Questionnaire was administered in school, using a paper and pen method, to elicit quantitative Likert scale (completely agree to completely disagree) data which was analysed by statistical programs. The Social Dilemma items are based on theoretical constructs informed by IC Thinking's 10 years of analysing value complexity in cross-cultural research.

\subsection{Procedure}

A single document (Annex 1) comprising the Depression Inventory and Social Dilemma Questionnaire was administered over two days. 15 boys were surveyed on day 1 and 22 on day 2. It took the boys approximately 30 minutes to complete the survey. The survey answers were compiled for statistical analysis using SPSS software.

\subsection{Results}

Both descriptive and inferential statistics were applied to analyse the results of the current study. A summary of the descriptive statistics of the study is provided in Table 1 below, which shows that the mean age of the sample group was 13.32. The majority of the participants i.e., $40.5 \%$ were from grade 9 while $37.8 \%$ were from grade 7 , and $16.2 \%$ were from grade 8 . 


\section{International Journal of Social Sciences and Management Review}

Volume: 05, Issue: 01 “January - February 2022”

ISSN 2582-0176

Table 1: Descriptive Statistics

\begin{tabular}{|l|l|l|}
\hline Variables & Mean & Standard Deviation (SD) \\
\hline Age (in years) & 13.32 & 3.36 \\
\hline Class & $F$ & $\%$ \\
\hline 7 & 14 & 37.8 \\
\hline 8 & 6 & 16.2 \\
\hline 9 & 15 & 40.5 \\
\hline
\end{tabular}

The Depression Inventory of the study group is given in Table 2 below. The mean depression score was 37.22 , falling in the category of moderate depression, with a standard deviation of

10.04. The majority of the participants i.e., $67.6 \%$ were categorized with moderate depression with $16.2 \%$ of participants falling in the mild depression category and another $16.2 \%$ in the severe depression category.

Table 2: Depression Inventory

\begin{tabular}{|l|l|l|}
\hline Depression & $\boldsymbol{F}$ & $\%$ \\
\hline Mild & 6.00 & 16.20 \\
\hline Moderate & 25.0 & 67.60 \\
\hline Severe & 6.00 & 16.20 \\
\hline Mean depression score & M & SD \\
& 37.22 & 10.04 \\
\hline
\end{tabular}

Table 3 summarizes the scoring of the Social Dilemma component of the questionnaire. Value complex scores ranged from 8.00 to 20.00 with a mean of 16.89 and a standard deviation of 2.66. The value monist score range was from 9.00 to 23.00 with a 14.35 mean and a standard deviation of 3.16. The mean score for the value complex component was slightly high as compared to the value monist, which shows the tendency of the respondents to keep in view more than one aspect while taking decisions in a particular social situation.

\section{Table 3: Social Dilemmas}

\begin{tabular}{|l|l|l|l|l|}
\hline Social Dilemmas & Minimum Score & Maximum Score & Mean & SD \\
\hline Value complex & 8.00 & 20.00 & 16.89 & 2.66 \\
\hline Value monist & 9.00 & 23.00 & 14.35 & 3.16 \\
\hline
\end{tabular}

Table 4 shows the correlation between depression and social dilemmas. Depression has a significant negative correlation with value complexity $(\mathrm{r}=-0.474)$. A non-significant positive correlation was found between value monist and depression. Furthermore, there was a significant negative correlation between value monist and value complex components.

Table 4: Correlation between Depression and Social Dilemmas

\begin{tabular}{|c|c|c|c|}
\hline \multirow{4}{*}{$\begin{array}{l}\text { Variables } \\
\text { Depression } \\
\text { (Pearson Correlation) }\end{array}$} & Depression & Value Monist & Value Complex \\
\hline & 1 & $-0.474 * *$ & 0.238 \\
\hline & & 0.003 & 0.156 \\
\hline & 37 & 37 & 37 \\
\hline
\end{tabular}




\section{International Journal of Social Sciences and Management Review}

\section{Volume: 05, Issue: 01 "January - February 2022"}

ISSN 2582-0176

\begin{tabular}{|c|c|c|c|}
\hline $\begin{array}{l}\text { Value monist } \\
\text { (Pearson Correlation) }\end{array}$ & $\begin{array}{r}-0.474 * * \\
0.003 \\
37\end{array}$ & $\begin{array}{r}1 \\
37\end{array}$ & $\begin{array}{r}-0.490 * * \\
0.002 \\
37\end{array}$ \\
\hline $\begin{array}{l}\text { Value complex } \\
\text { (Pearson Correlation) }\end{array}$ & $\begin{array}{r}0.238 \\
0.156 \\
37\end{array}$ & $\begin{array}{r}-0.490 * * \\
0.002 \\
37\end{array}$ & 1 \\
\hline
\end{tabular}

** Correlation is significant at the 0.01 level (2 Tailed)

\subsection{DISCUSSION}

The findings of this study add to the previous body of literature by identifying depression as one of the stressors that can impact IC. Although, Nemr and Savage (2019) highlight stressors such as family issues, traumatic events, and threats to identity as factors that increase the vulnerability of individuals to low complexity and constrained thinking, they do not focus on mental health issues. The impact of emotional well-being on IC intervention is examined by Kargar et al. (2013) in a study on adolescents, however, the study has limitations as it does not establish the baseline levels prior to training on critical and creative thinking.

A negative correlation between two variables shows an inverse relationship where when one variable increases, the other decreases, and vice-versa. For example, there is a significant negative correlation between value monist and value complex components. More importantly, there is a significant negative correlation between depression and value complexity, which indicates that if value complexity is high, then depression is low. On the other hand, a positive correlation, where both variables move in the same direction, is observed between the value monist component and depression, although the correlation is non-significant. A correlation does not necessarily show causation between two variables; however, it does demonstrate an observable pattern.

The significant negative correlation between depression and value complexity in this study can be understood in the context of the work done by Fearon and Boyd Mac-Millan (2016) who focus on the impact of stress, a key determinant of emotional well-being, in the context of conflict. The decrease in IC levels in times of high stress may also explain the link between low IC with high depression, as stress and depression often coexist. However, it remains to be seen whether depression follows a similar pathway as stress mechanism whereby IC levels change based on whether a situation is perceived as a challenge or threat leading to activation of the SAM axis (Liht and Savage, 2013) or HPA and SAM axes (threat response) that can impact emotional well-being (Blasovich and Mendes 2010). This study, therefore, provides a basis for expanding on Fearon and Boyd Mac-Millan (2016) assessment that "interventions that seek to leverage gains in integrative complexity must also learn how to leverage stress", to include other components of mental health such as depression to limit disruption of IC. The correlation between depression and IC is useful for not only times of conflict, but also for developing high IC in adolescents for building value pluralism for collaboration and compromises in group settings for personal success in family and future professional settings leading to positive contribution as members of society. 


\title{
International Journal of Social Sciences and Management Review
}

\author{
Volume: 05, Issue: 01 “January - February 2022"
}

ISSN 2582-0176

Moreover, the establishment of a link between depression and IC is important as it will help inform the development of future IC interventions to reduce radical thinking and vulnerability to violence. For example, if teaching 20 hours of critical and creative skills to 40 students in Tehran (Kargar et al., 2013) resulted in an increase in psychological well-being, it will be interesting to see the impact of adding workshops on emotional well-being, focusing on content for recognizing and addressing symptoms of depression as well as self-help coping tips, and then subsequently measuring IC and well-being indicators. Similarly, there is scope for addressing mental health issues such as depression in the interventions being undertaken by Peracha et al. (2016) in Pakistan at selected mainstream government schools. By incorporating material on mental health awareness, efforts to promote skills in adolescents linked to IC such as critical thinking, logical reasoning, and value pluralism may yield better results.

As the sample size of this study was small and there was no control group, causal inferences require caution. Limitations of this study can be addressed by repeating it with a larger sample size including both genders and adding a control group in the study design. This will open avenues for further research on IC intervention studies including the depression component, with long-term monitoring of benefits over 6 and 12 months to assess improvements in core IC skills, psychological well-being, and lowered vulnerability to radical views.

Given the rise of mental health issues in youth all over the world and depression being a leading cause of illness in adolescents (WHO, 2020), this study has implications for further research on the overall incidence of depression in school going students. The study by Khalid et al. (2019) on school children in northern Pakistan showing depression in $17.2 \%$ of participants, along with the depression rates identified in this study, may be indicative of a wider problem, especially in the context of rising poverty and morbidity associated with the Covid-19 pandemic in Pakistan. In a society where there is limited recognition and understanding of mental health issues, adolescent depression is often unrecognized. Therefore, there is an urgent need for studies on the incidence of depression in teenagers, so that they can be provided support for emotional and physical well-being as part of their school curriculum alongside IC interventions. The relevance of socio-economic background also requires further investigation as the teenagers in the school study sample were from lowincome families, which have faced greater economic hardship during the Covid pandemic. It may be interesting to see the results in different socio-economic backgrounds and also gender comparison studies.

\subsection{CONCLUSION}

This study shows a significant negative correlation between depression and value complexity in teenagers. The findings are noteworthy as they can help inform the design of suitable IC interventions for this age group. As low IC increases vulnerability to extremist views, measures to address depression may have a beneficial impact on IC and hence lower the chances for teenagers becoming easy recruits for radical socio-religious groups. Thus, this research suggests the need to explore activities for school-age children to reduce the impact of depression on their cognitive ability. Interventions at an early age to build high IC will 


\section{International Journal of Social Sciences and Management Review}

Volume: 05, Issue: 01 “January - February 2022”

ISSN 2582-0176

provide an avenue to reduce extremist tendencies, and instead promote tolerance and pluralism in society.

\section{REFERENCES}

Bekes, V., \& Suedfeld, P. (2019). Integrative Complexity. In V. Zeigler-Hill \& T. K. Shackelford (Eds.) Encyclopedia of Personality and Individual Differences, (pp. 1-5) Switzerland: Springer. https://doi.org/10.1007/978-3-319-28099-8_1942-1

Blascovich, J., \& Mendes, W.B. (2010). Social Psychophysiology and Embodiment. In S. T. Fiske, D. T. Gilbert, \& G. Lindzey (Eds.), Handbook of Social Psychology, (pp. 194227). John Wiley \& Sons, Inc. https://doi.org/10.1002/9780470561119.socpsy001006

Boyd Mac-Millan, E. (2016). Increasing Cognitive Complexity and Collaboration Across Communities: Being Muslim Being Scottish. Journal of Strategic Security, 9(4), 79110. https://doi.org/10.5038/1944-0472.9.4.1563

Boyd Mac-Millan, E., Campbell, C., \& Furey, A. (2016). An IC Intervention for PostConflict Northern Ireland Secondary Schools. Journal of Strategic Security, 9(4), 111-124. https://doi.org/10.5038/1944-0472.9.4.1558

Boyd Mac-Millan, E., Fearon, P., Ptolomey, A., \& Mathieson, L. (2016). I SEE! Scotland: Tackling Sectarianism and Promoting Community Psychosocial Health. Journal of Strategic Security, 9(4), 53-78. https://doi.org/10.5038/1944-0472.9.4.1556

Centers for Disease Control and Prevention (CDC). (2021, March 22). Data and Statistics on Children's Mental Health. https://www.cdc.gov/childrensmentalhealth/data.html

Cortina, M., Sodha, A., Fazel, M., \& Ramchandani, P. (2012). Prevalence of Child Mental Health Problems in Sub-Saharan Africa. Arch Pediatr Adolesc Med. 166(3): 276-281. https://jamanetwork.com/journals/jamapediatrics/fullarticle/1107721

DW. (2020, May 19). Mental health problems a growing issue for European teens: WHO. Retrieved from https://www.dw.com/en/mental-health-problems-a-growing-issue-foreuropean-teens-who/a-53503149

Fearon, P., \& Boyd Mac-Millan, E. (2016) Complexity under Stress: Integrative Approaches to Overdetermined Vulnerabilities. Journal of Strategic Security, 9 (4): 11-31. http://dx.doi.org/10.5038/1944-0472.9.4.1557

Gruenfeld, D. H., \& Hollingshead, A. B. (1993). Socio-cognition in workgroups: The evolution of group integrative complexity and its relation to task performance. Small Group Research, 24, 383-405.

IC Thinking (Cambridge). (2018). Select Publications. https://icthinking.org/publications-1

Kargar Rezaei, F., Ajilchi, B., Kalantar Choreishi, M. \& Zohoori Zangene, Z. (2013). The Effect of Teaching Critical and Creative Thinking Skills on the Locus of Control and 


\section{International Journal of Social Sciences and Management Review}

Volume: 05, Issue: 01 “January - February 2022”

ISSN 2582-0176

Psychological Well-Being in Adolescents. Procedia- Social and Behavioral Sciences, 82, 51-56.

Khalid, A., Qadir, F., Chan, S. \& Schwannauer, M. (2019). Adolescents' mental health and well-being in developing countries: a cross-sectional survey from Pakistan. Journal of Mental Health, 28(4),389-396.

Liht, J., \& Savage, S. (2013). Preventing Violent Extremism through Value Complexity: Being Muslim Being British. Journal of Strategic Security, 6(4), 44-66. https://digitalcommons.usf.edu/jss/vol6/iss4/3/

National Institute of Mental Health (NIMH). (2021, October). Prevalence of Major Depressive Episode Among Adolescents. NIMH » Major Depression (nih.gov)

Nemr, C., \& Savage, S. (2019). Integrative Complexity Interventions to Prevent and Counter Violent Extremism. Global Center on Cooperative Security, (pp. 1-7). JSTOR. https://www.jstor.org/stable/pdf/resrep20332.pdf

Peracha, F.N., Khan, R.R., Savage, S. (2016). Sabaoon: Education Methods Successfully Countering and Preventing Violent Extremism. In S. Zeiger (Ed), Expanding Research on Countering Violent Extremism (pp 85- 104). Hedayah \& Edith Cowan University.

Porter, C. A., \& Suedfeld, P. (1981). Integrative complexity in the correspondence of literary figures: Effects of personal and societal stress. Journal of Personality and Social Psychology, 40, 321-330.

Public Health England. (2019, October 25). Guidance Children and Young People. Retrieved from https://www.gov.uk/government/publications/better-mental-health-jsnatoolkit/5-children-and-youngpeople\#: :text=The\%20most $\%$ 20recent $\% 20$ survey $\% 20$ of, $2 \% 20 \mathrm{or} \% 20 \mathrm{~m}$ ore $\% 20 \mathrm{~m}$ ental\%20disorders.

Savage, S. (2008). Mapping Fundamentalisms: The Psychology of Religion as a SubDiscipline in the Understanding of Religiously Motivated Violence. International Journal for the Psychology of Religion, 30(1), 75-91.

Savage, S. (2012). Four Lessons from the Study of Fundamentalism and Psychology of Religion. Journal of Strategic Security, 4, 131-150. DOI: http://dx.doi.org/10.5038/1944-0472.4.4.6

Savage, S., \& Fearon, P. A. (2021). Increasing cognitive complexity and meta-awareness among at-risk youth in Bosnia-Herzegovina in order to reduce risk of extremism and interethnic tension. Peace and Conflict: Journal of Peace Psychology, 27(2), 225-239. https://doi.org/10.1037/pac0000557

Savage, S. \& Liht, J. (2009). Radical Religious Speech: The Ingredients of a Binary World View. In Extreme Speech and Democracy, Ivan Hare \& James Weinstein (Eds) Oxford: Oxford University Press. 


\section{International Journal of Social Sciences and Management Review}

Volume: 05, Issue: 01 “January - February 2022”

Savage, S., Khan, A., \& Liht, J. (2014). Preventing Violent Extremism in Kenya through Value Complexity: Assessment of Being Kenyan Being Muslim. Journal of Strategic Security, 7(3), 1-26. https://doi.org/10.5038/1944-0472.7.3.1

Siddiqui, S. \& Shah, S.A.I. (1997) Siddiqui-Shah Depression Scale (SSDS): Development and Validation. Psychology \& Developing Societies, 9, 2. http://www.scalesandmeasures.net/files/files/Siddiqui-

Shah\%20Depression\%20Scale\%20(1997).pdf

Suedfeld, P. (1985). APA presidential addresses: The relation of integrative complexity to historical, professional, and personal factors. Journal of Personality and Social Psychology, 49(6),1643.

Suedfeld, P., \& Tetlock, P. (1977). Integrative complexity of communications in international crises. Journal of Conflict Resolution, 21, 169-184.

Suedfeld, P., Wallace, M. D., \& Thachuk, K. L. (1993). Changes in integrative complexity among Middle East leaders during the Persian Gulf crisis. Journal of Social Issues, 49(4), 183-199.

World Health Organization (WHO). (2020, September 28). Adolescent health and development. https://www.who.int/news-room/fact-sheets/detail/adolescent-mentalhealth

World Health Organization (WHO). (nd) WHO Pakistan celebrates World Mental Health Day. Retrieved from http://www.emro.who.int/pak/pakistan-news/who-pakistancelebrates-world-mental-health-day.html 
International Journal of Social Sciences and Management Review

Volume: 05, Issue: 01 “January - February 2022”

\section{Annex 1}

Siddiqui Shah Depression Scale (SSDS)
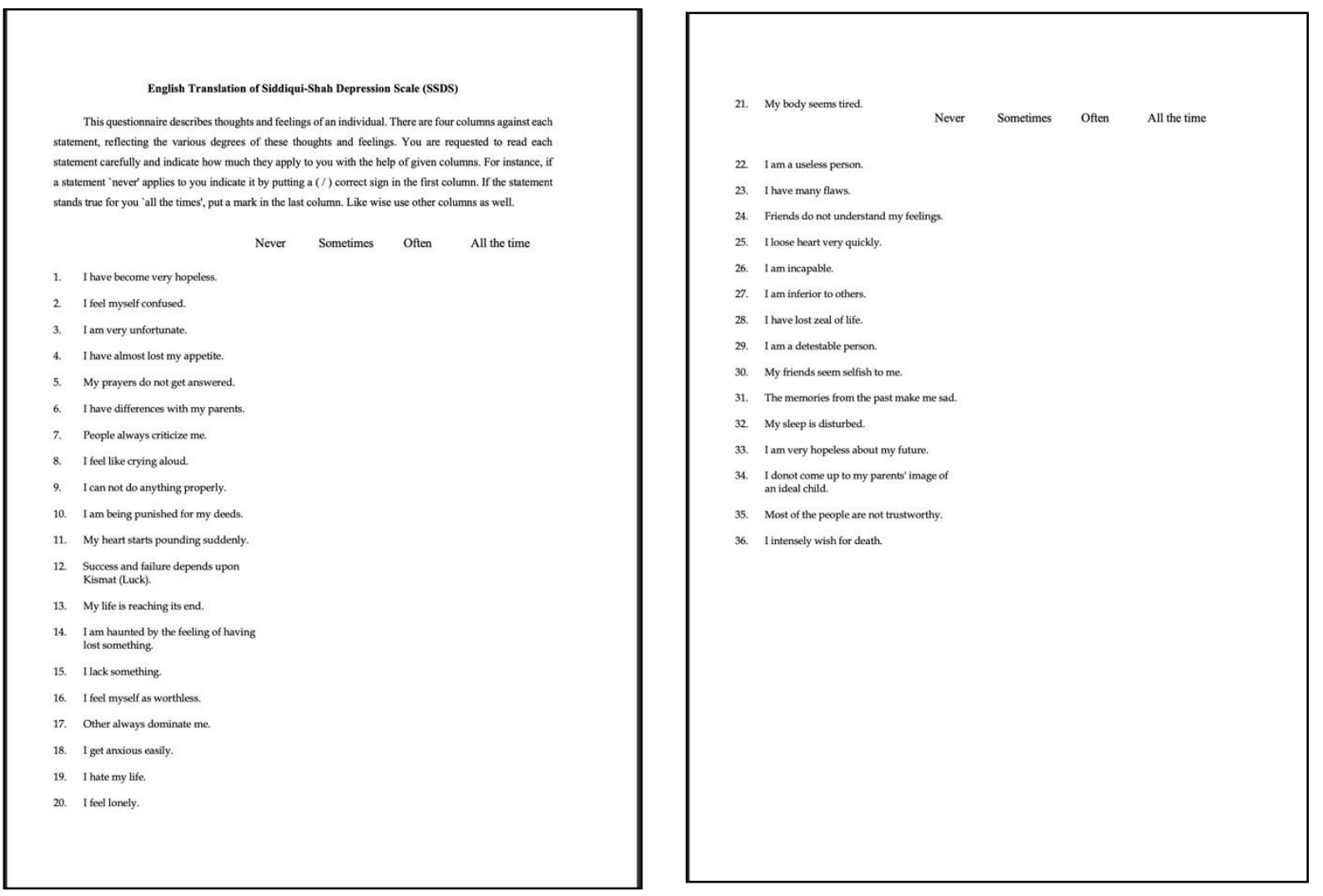


\section{International Journal of Social Sciences and Management Review}

Volume: 05, Issue: 01 “January - February 2022”

ISSN 2582-0176

\section{Social Dilemmas Questionnaire}
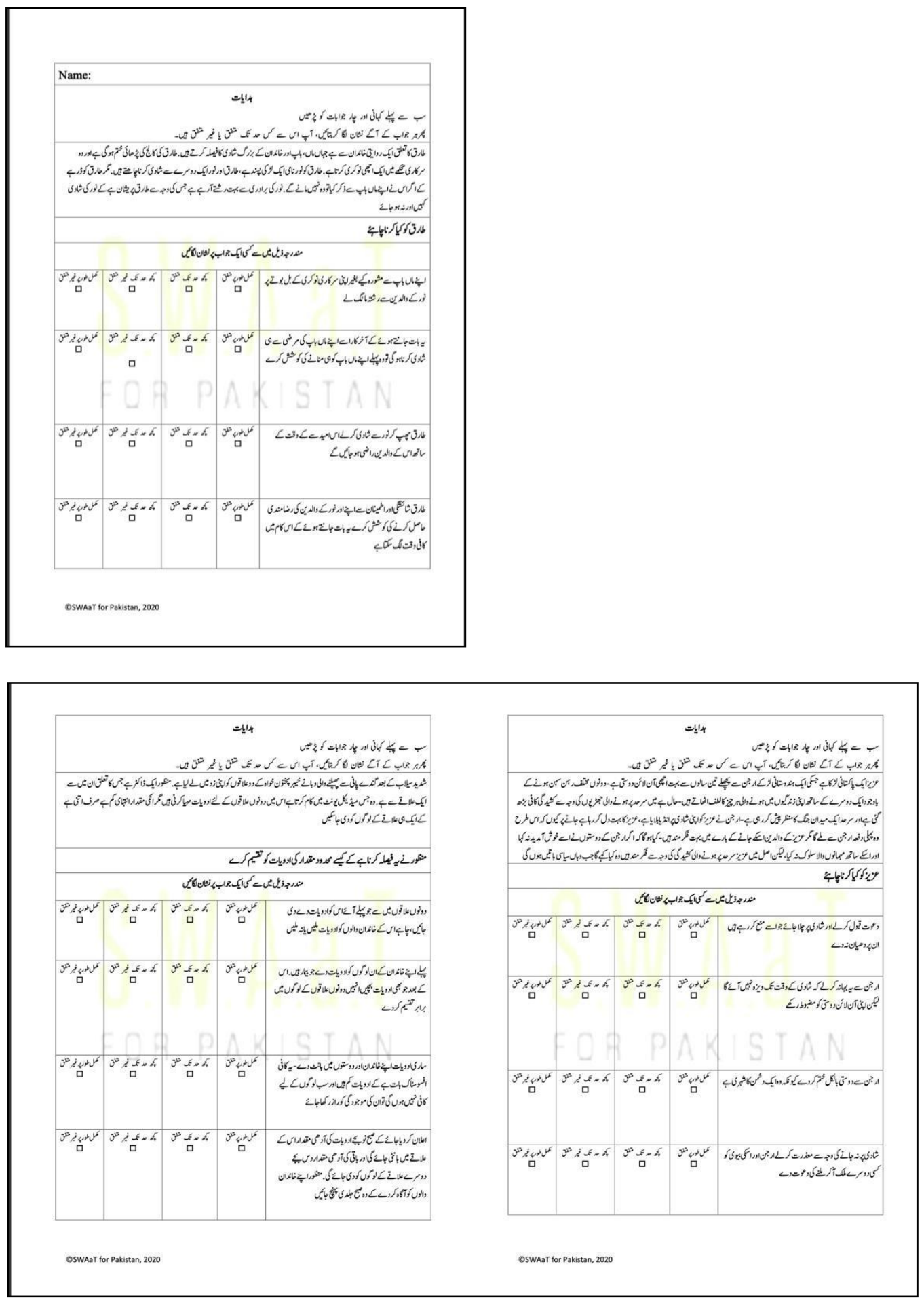